\title{
Analysis of Interferential Current Therapy-Induced Skin Changes in Healthy Korean Men
}

\author{
So-Jung Kim ${ }^{1}$, Seung-Min Yang ${ }^{1 *}$, Ju-Hyun Kim${ }^{2}$, Jeong-Uk Lee ${ }^{3}$, Mee-Young Kim1, \\ Lim-Kyu Lee ${ }^{1,4}$, Byoung-Sun Park ${ }^{1}$, Won-Deok Lee ${ }^{1}$, Ji-Woong Noh ${ }^{1}$, Yong-Sub Shin ${ }^{1}$, \\ Doo-Ho Kim ${ }^{1}$, Il-Hyun Kim${ }^{1}$, Kong-Sook Noh ${ }^{1}$, Junghwan Kim ${ }^{5}$
}

${ }^{1}$ Laboratory of Health Science \& Nanophysiotherapy, Department of Physical Therapy, Graduate School, Yongin University, Yongin-si, Republic of Korea; ${ }^{2}$ Department of Physical Therapy, College of Health Welfare, Wonkwang Health Science University, Iksan-si, Republic of Korea; ${ }^{3}$ Department of Physical Therapy, College of Health Science, Honam University, Gwangju-si, Republic of Korea; ${ }^{4}$ The Team of Safety and Quality Management, Yeongwol Combined Cycle Power Plant Division, Korea Southern Power Plant, Yeongwol-gun, Republic of Korea; ${ }^{5}$ Department of Physical Therapy, College of Public Health \& Welfare, Yongin University, Yongin-si, Republic of Korea

Correspondence to: Junghwan Kim, junghwankim3@yongin.ac.kr Keywords: Interferential Current Therapy, Korean Men, Skin Received: October 8, $2018 \quad$ Accepted: November 27, $2018 \quad$ Published: November 30, 2018

Copyright $\odot 2018$ by authors and Scientific Research Publishing Inc. This work is licensed under the Creative Commons Attribution International License (CC BY 4.0). http://creativecommons.org/licenses/by/4.0/

\section{(c) (i) Open Access}

\section{ABSTRACT}

We examined the changes in numerous skin conditions before and after the application of interferential current therapy to various regions of healthy male bodies. In this study, we assessed the differences in the skin's sebum, moisture levels, pores, wrinkles, pigmentation, and elasticity on the shoulders, lower back, and the knees of Korean males in their 20s. A total of 30 healthy males were included in the study. We used a skin diagnosis meter as a device for measuring the state of the skin. A statistical difference was found when comparing the pre- and post-measurement values in regards to the moisture levels, wrinkles, and pigmentation. In the correlation analysis results, the sebum and pigmentation, moisture levels and wrinkles, moisture levels and pigmentation, and moisture levels and elasticity were all positively correlated, respectively. The results of this study partially suggest that a change in skin condition is associated with external stimulation. The study also found that the effects of the application of interferential current therapy on the various skin conditions may differ depending on the region of the body that the application is conducted as well.

\section{INTRODUCTION}

Potential options for the physical therapy management of muscle, soft tissue, control of pain, edema, ${ }^{\star}$ The first 2 authors (Kim S.-J. and Yang S.-M.) contributed equally to this work. 
and neurological impairment includes transcutaneous electrical nerve stimulation, ultrasounds, hot packs, as well as interferential current therapy [1-4]. Therapists often use interferential current therapy for the treatment and alleviation of skeletal muscle pain [5]. The therapy involves the application of medium frequency alternating electric currents via the skin $[5,6]$. The medium frequency current penetrates the tissues with very little resistance, whereas the resulting interference current is within a range that creates effective stimulation of the biological tissues [3]. Beatti reported that the highest voltages were recorded in the superficial tissues, and the lowest voltages were recorded in muscle [2]. The principal components of an interferential unit are a pair of signal generators; the output of one is oscillating at the fixed frequency of $4000 \mathrm{~Hz}$ while the other is a variable oscillation between the frequencies of 4000 and $4100 \mathrm{~Hz}[2,4]$. Two pairs of electrodes, which convey separately the amplified output of the oscillators, are aligned on the skin so that the currents flowing between each pair intersect and interfere within the intended treatment region [4]. A resultant current of low frequency is generated that alternates at $0-250 \mathrm{~Hz}[2,7,8]$. The use of two currents at around $4 \mathrm{kHz}$ was chosen to overcome skin impedance so that the current could penetrate into the deeper tissues [9]. For treatment, the area of skin to be treated is cleaned with soap and water to reduce linear electrical resistance, and the electrodes are fixed to the skin using medical tape. Some ICT apparatus is supplied with electrodes that are held in place by suction cups, which are evacuated using a vacuum pump [6]. This is accomplished by placing a suction pad, containing an electrode covered with a synthetic sponge onto the skin surface above the muscle region that is causing pain [10]. Many centers use non-disposable suction pads and sponges, which can be re-used following a disinfection process. Disposable alternatives are available, but they are rarely used due to the higher associated costs. Some interferential therapy machines also rely on the use of a water seal to facilitate the attachment of the suction cup to the skin [10]. The water is held in a detachable reservoir located on the machine, but this reservoir could potentially be contaminated with micro-organisms. In common with other reusable medical devices that make direct contact with the skin such as ultrasound probes and TENS sponges, the interferential therapy machine may transfer micro-organisms from one patient to another $[10,11]$. One study reported that single use electrode pads and sponges could be used to avoid cross-contamination; alternatively, disinfection of the suction cups using $70 \% \mathrm{v} / \mathrm{v}$ isopropyl alcohol should take place following each use [10]. We studied how the skin is influenced by the interferential current therapy that used water with a sponge that turned out to be water [12]. Treffene tested the ICT spread in a homogenous water medium. Minimum stimulation occurred at the intersection of the two circuits, which were at a $90^{\circ}$ angle, and a maximum stimulation occurred along the diagonals, which were at a $45^{\circ}$ angle, between the two circuits [13]. There is a paper on the immediate effects on the skin condition after the application of electrical therapy [14]. Therefore, in the present study, we divided the faces in detail and compared them before and after ICT. The purpose of this study was to establish a map of the skin of shoulder, back, and knee using six biophysical parameters to study various aspects of the skin-sebum, moisture, pores, wrinkles, pigmentation, and elasticity.

\section{METHODS}

\subsection{Participants}

Thirty healthy male subjects aged 20 - 29 were enrolled in the present study. None of the subjects had any skin disorders (Table 1). Two areas, the face and the neck, were examined before and after interferential current therapy (ICT). No skin care products had been applied for at least $24 \mathrm{~h}$ beforehand, and the skin had not been washed with soap or surfactants for at least $2 \mathrm{~h}$ before the experiment. The participants were asked to complete a questionnaire during individual in-depth interviews, which took $30 \mathrm{~min}$ per person [15].

\subsection{Measurements}

All measurements were performed with the participants comfortably in a supine position. The face 
Table 1. The general characteristics of men in their $20 \mathrm{~s}$.

\begin{tabular}{|c|c|c|}
\hline Variable & Classification & \\
\hline Age (yrs) & & $24.1 \pm 0.3$ \\
\hline Height $(\mathrm{cm})$ & & $174.8 \pm 0.9$ \\
\hline Weight (kg) & & $74.2 \pm 1.2$ \\
\hline BMI $\left(\mathrm{kg} / \mathrm{m}^{2}\right)$ & & $23.0 \pm 0.6$ \\
\hline \multirow[t]{2}{*}{ Gender (\%) } & Male & $30(100.0)$ \\
\hline & Female & - \\
\hline \multirow[t]{4}{*}{ Blood type (\%) } & $\mathrm{AB}$ & $2(6.7)$ \\
\hline & A & $8(26.7)$ \\
\hline & B & $14(46.7)$ \\
\hline & $\mathrm{O}$ & $6(20.0)$ \\
\hline \multirow[t]{2}{*}{ Smoking (\%) } & Smoker & $15(50.0)$ \\
\hline & Nonsmoker & $15(50.0)$ \\
\hline \multirow[t]{4}{*}{ Drinking (\%) } & Yes & $30(100.0)$ \\
\hline & No & - \\
\hline & 1 bottle/week & $16(53.3)$ \\
\hline & 2 bottle/week & $14(46.7)$ \\
\hline PSQI (score) & & $1.8 \pm 0.1$ \\
\hline \multirow[t]{3}{*}{ Skin injury (\%) } & Injuries experience & $18(60.0)$ \\
\hline & Injuries inexperience & $5(16.7)$ \\
\hline & Don't know & $7(23.3)$ \\
\hline \multirow[t]{4}{*}{ Type of skin injury (\%) } & Abrasion & $12(40.0)$ \\
\hline & Burns & $3(10.0)$ \\
\hline & Incised wound & $3(10.0)$ \\
\hline & Nothing & $12(40.0)$ \\
\hline
\end{tabular}

All data were presented as the mean \pm SE. BMI, body mass index; PSQI, Pittsburgh sleep quality index.

was divided into two areas, the shoulder joint, low back, and the knee joint. Repeated measurements were taken for each study subject. Electrical stimulation was conducted at the regions of the shoulder joint, lower back and knee joint using the ICT (ERBE, Elektromedizin Tubingen, Germany), as well as the suction intensity is composed of $1-4$ intensity, which it used the intensity that the application feels comfortable with subjects [5]. It was sit used to stimulate line voltage $220 \mathrm{~V}$, Line Frequency $60 \mathrm{~Hz}$, input current $0.35 \mathrm{~A}$ and electrical stimulus was conducted for $15 \mathrm{~min}$ by setting $\min 50 \mathrm{~Hz}$ - mix $150 \mathrm{~Hz}$ frequency [5]. A skin diagnosis meter (SDM, 2016 BOMTECH ver. 3.20) was used to measure the skin's surface sebum content, moisture, pores, pigmentation, wrinkles, and elasticity of the shoulder, back, and knee. ICT was applied to each region for $15 \mathrm{~min}$, with the distance between the measuring device and the subject's skin being set at $20 \mathrm{~cm}$. During the measurement of the skin, the normal force level was $0.7 \mathrm{~N}$. The same investigator performed all procedures in a room kept at a constant temperature $\left(22^{\circ} \mathrm{C}-24^{\circ} \mathrm{C}\right)$ and humidity $(45 \%-55 \%)$. The skin testing machine is made up of two meters: the E-cam measures sebum, pigmentation, and pores, and the P-sensor measures moisture and elasticity $[16,17]$. The E-cam measures the skin using an X80 lens and measures the amount of sebum using UV light. The meter measures the dermis layer of pigmentation, wrinkle length, and pore size using general light $[16,17]$. The measurement area is in the range of $4 \mathrm{~cm}^{2}$. The $\mathrm{P}$-sensor uses an electrode to send a current through the skin surface and the 
skin reacts to the electricity. It creates a calculation using the values of the skin's reaction to the electricity. To measure sebum, the meter uses skin UV to see how much oil is contained in the targeted area [16-18].

\subsection{Clinical Assessments}

We used the sebum arbitrary units (SAUs); the values are 0 - 650 (a little sebum), 650 - 1200 (normal), 1200 - 5000 (a lot of sebum), and more than 5000 (excessive sebum). To make use of the moisture arbitrary units (MAUs), set the values to $1 \%-100 \%[16,17]$. These values are $0-19$ (very dry), $20-29$ (dry), 30 - 39 (moderate), 40 - 49 (plenty of moisture), and more than 50 (a high amount of moisture) [16, 17]. The P-sensor meter uses a rectangular spring to measure elasticity. When the spring contacts the skin, it measures how much the sticky part of the spring can be forced into the skin. To make use of the elasticity arbitrary units (EAUs), set the values to $1 \%-100 \%$. These values are 0 - 24 (very low elasticity), $25-34$ (low), 35 - 44 (moderate), 45 - 54 (high), and more than 55 (very high) $[16,17,19]$. These values were expressed on a graph. The graph showed the skin surface's reactivity value according to the distance from the point measured. The data values were measured using Microsoft Office PowerPoint 2007. Based on the $\mathrm{x}$-axis of 0 to $25.5 \mathrm{~cm}$ and the $\mathrm{y}$-axis of 0 to $20 \mathrm{~cm}$, each coordinate was set on the basis of each vertex of the graph. By connecting the set coordinates, we found the area of the graph $[16,17]$. Next, each vertex of the graph was calculated using digital calipers (Industrial Instrument Company, Mitutoyo, Japan), and the area was calculated using OriginPro 2016 (64 bit). Pigmentation was measured using general light [16, 20, 21]. The pigmentation arbitrary units (PiAUs) are set at values of $1-10$ grade: $0-2$ (favorable), $2-4$ (moderate), 4 - 6 (mild), and 6 - 10 (severe). To make use of the wrinkle arbitrary units (WAUs), set the values to 1 - 10 grade. These are 0 - 2 (favorable), 2 - 3 (early mild wrinkles), 3 - 5 (early severe wrinkles), 5 6 (thicker mild wrinkles) $[16,17,22]$, and $6-10$ (thicker severe wrinkles). To make use of the pore arbitrary units (PAUs), set the values to 1 - 10 grade. These are 0 - 2 (small size), 2 - 4 (moderate), 4 - 6 (broadish), 6 - 8 (large), and 8 - 10 (very large) [16, 17].

\section{RESULTS}

\subsection{Changes in the Skin Condition of Sebum and Moisture in Response to the Application of ICT in Relation to Various Body Regions}

General characteristics of the thirty healthy subjects are noted in Table 1. No statistical difference in sebum was found between pre- and post-measured values in the shoulder, back, and shin, which can be seen in Figure 1(a). There was a statistical difference in moisture levels found between the pre-measured lower back, which was $66.22 \pm 1.07$, and the post-measured lower back, which was $68.70 \pm 1.45$. Also, there was a statistical difference noted in the moisture levels of the knee. The pre-measured moisture level for the knee was $57.38 \pm 1.54$, and the post-measured level for the knee was $64.18 \pm 1.14$. In both cases, the value of $\mathrm{p}$ was $\mathrm{p}<0.05$. The values in the lower back and the knee region are depicted in Figure 1(b).

\subsection{Changes in the Skin Condition of Pore and Wrinkle in Response to the Application of ICT in Relation to Various Body Regions}

No statistical difference in pore was found between pre- and post-measured values in the shoulder, back, and shin, as is demonstrated in Figure 1(c). In contrast, a statistical difference in wrinkle was found between pre-measured and post-measured values in the shoulder, low back and knee region. The pre-measured values for wrinkles were $3.41 \pm 0.27$ for the shoulder, $4.19 \pm 0.28$ for the lower back, and $3.53 \pm 0.41$ for the knee (Figure 2). The post-measured values were $5.11 \pm 0.40$ for the shoulder, $5.44 \pm$ 0.27 for the lower back, and $5.12 \pm 0.25$ for the knee, where $\mathrm{p}<0.05$ (Figure 2).

\subsection{Changes in the Skin Condition of Pigmentation and Elasticity in Response to the Application of ICT in Relation to Various Body Regions}

A statistical difference in pigmentation was found between pre-measured and post-measured values 


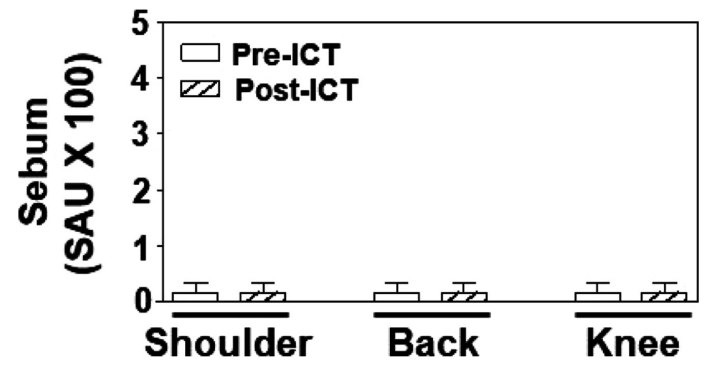

(a)

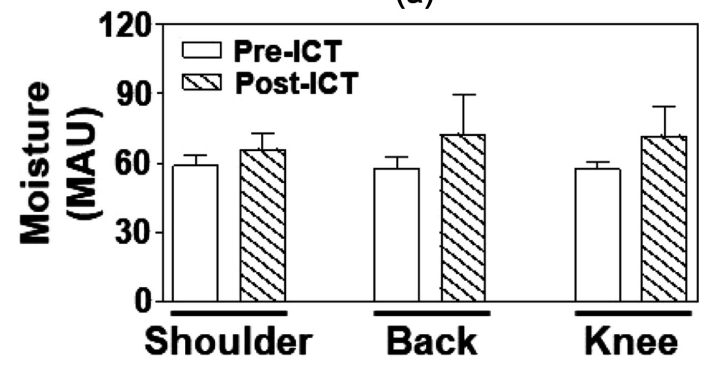

(b)

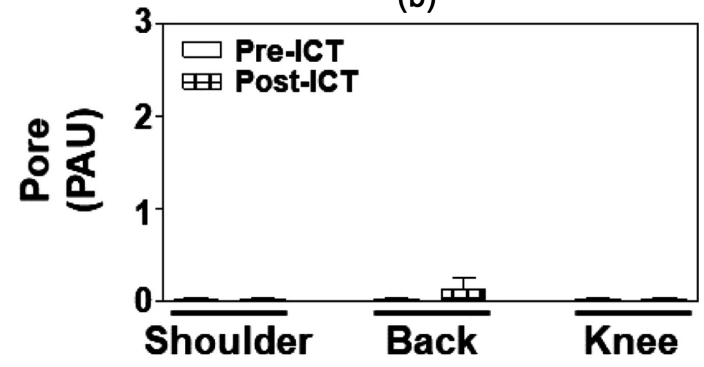

(c)

Figure 1. Differences in the sebum, moisture, and pore of the skin's surface for the shoulder, back, and knee. Each bar represents the mean \pm SE. SAU, sebum arbitrary units; MAU, moisture arbitrary units; PAU, pore arbitrary units; ICT, interferential current therapy, Pre- and Post-ICT, before and after ICT application.

in the shoulder, lower back and knee region, as can be seen in Figure 2. The pre-measured values of pigmentation in the shoulder were $2.48 \pm 0.27$. In the lower back, the pre-measured value was $2.88 \pm 0.33$, and the knee was $2.46 \pm 0.31$. The post-measured value of pigmentation in the shoulder was $5.41 \pm 0.69$, and in the lower back, it was $4.86 \pm 0.46$. The post measured value for pigmentation in the knee was $4.78 \pm 0.33$. The value of $\mathrm{p}$ for all three was $\mathrm{p}<0.05$. A statistical difference in elasticity was found between pre-measured $(58.58 \pm 2.56)$ and post-measured $(65.11 \pm 1.52$, where $\mathrm{p}<0.05)$ values in the knee region, as demonstrated in Figure 3.

\subsection{Correlation of Skin Conditions among Variables before the Application of ICT}

The Pearson's correlation coefficients among components before the application of ICT are shown in Table 2. In this study, the variables of sebum, moisture, pore, wrinkle, pigmentation, and elasticity were classified. All variables were input as continuous data. In the correlation analysis results, sebum and 


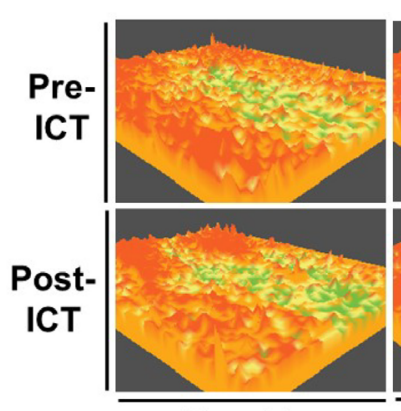

Shoulder

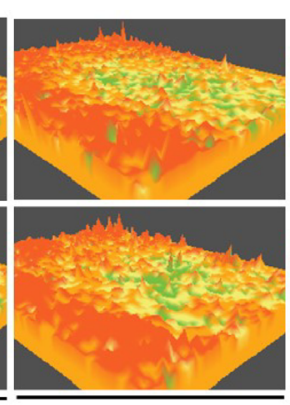

Back

(a)

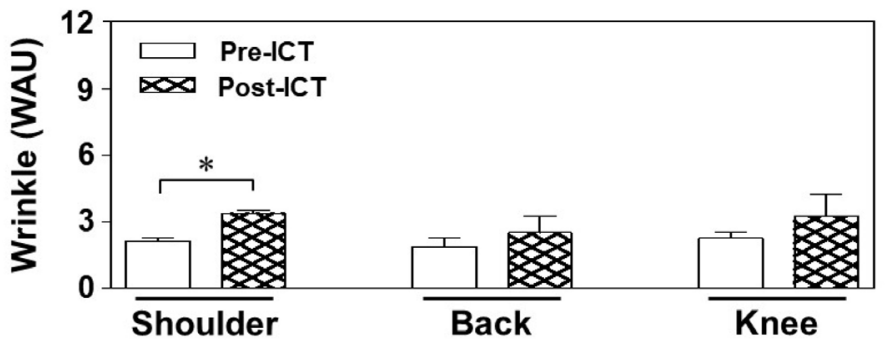

(b)

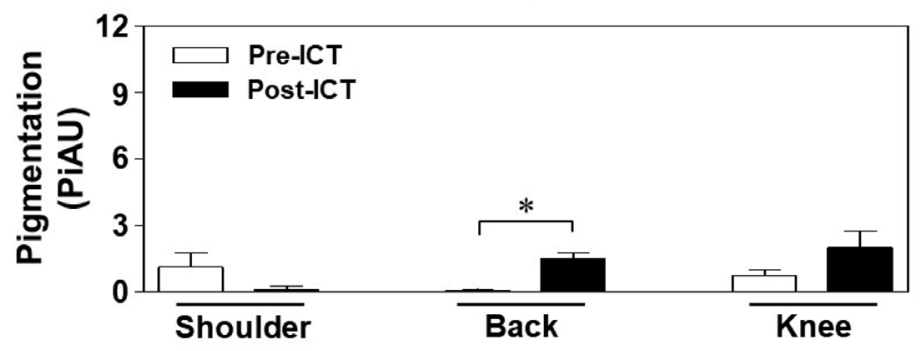

(c)

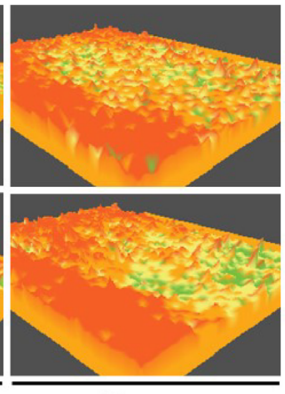

Knee 


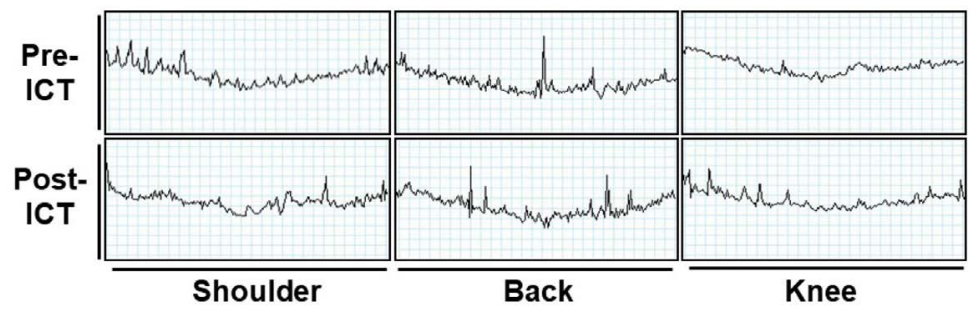

(a)

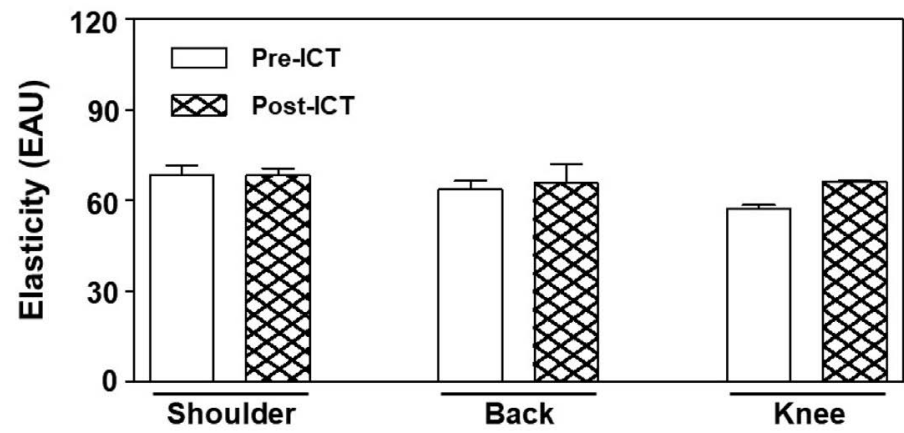

(b)

Figure 3. Differences in the elasticity of the skin's surface for the shoulder, back, and knee. Each bar represents the mean \pm SE. EAU, elasticity arbitrary units; ICT, interferential current therapy, Pre- and Post-ICT, before and after ICT application.

Table 2. Pearson's correlation coefficient for skin conditions of before and after ICT.

\begin{tabular}{|c|c|c|c|c|c|c|}
\hline & \multicolumn{6}{|c|}{ Before interferential current therapy } \\
\hline & Sebum & Moisture & Pore & Wrinkle & Pigmentation & Elasticity \\
\hline Sebum & 1 & & & & & \\
\hline Moisture & 0.301 & 1 & & & & \\
\hline Pore & -0.142 & 0.122 & 1 & & & \\
\hline Wrinkle & 0.300 & $0.564^{\star *}$ & 0.184 & 1 & & \\
\hline Pigmentation & $0.433^{\star}$ & $0.496^{\star *}$ & 0.128 & $0.814^{\star \star}$ & 1 & \\
\hline \multirow[t]{3}{*}{ Elasticity } & 0.046 & $0.493^{\star *}$ & 0.283 & $0.554^{\star \star}$ & 0.159 & 1 \\
\hline & \multicolumn{6}{|c|}{ After interferential current therapy } \\
\hline & Sebum & Moisture & Pore & Wrinkle & Pigmentation & Elasticity \\
\hline Sebum & 1 & & & & & \\
\hline Moisture & 0.132 & 1 & & & & \\
\hline Pore & 0.017 & 0.153 & 1 & & & \\
\hline Wrinkle & 0.077 & $0.380^{*}$ & 0.131 & 1 & & \\
\hline Pigmentation & 0.005 & $0.512^{\star *}$ & 0.055 & $0.797^{\star \star}$ & 1 & \\
\hline Elasticity & 0.273 & 0.288 & 0.222 & 0.172 & 0.002 & 1 \\
\hline
\end{tabular}

Data presented as Pearson's correlation coefficients. ${ }^{*} \mathrm{p}<0.05,{ }^{* *} \mathrm{p}<0.01$. 


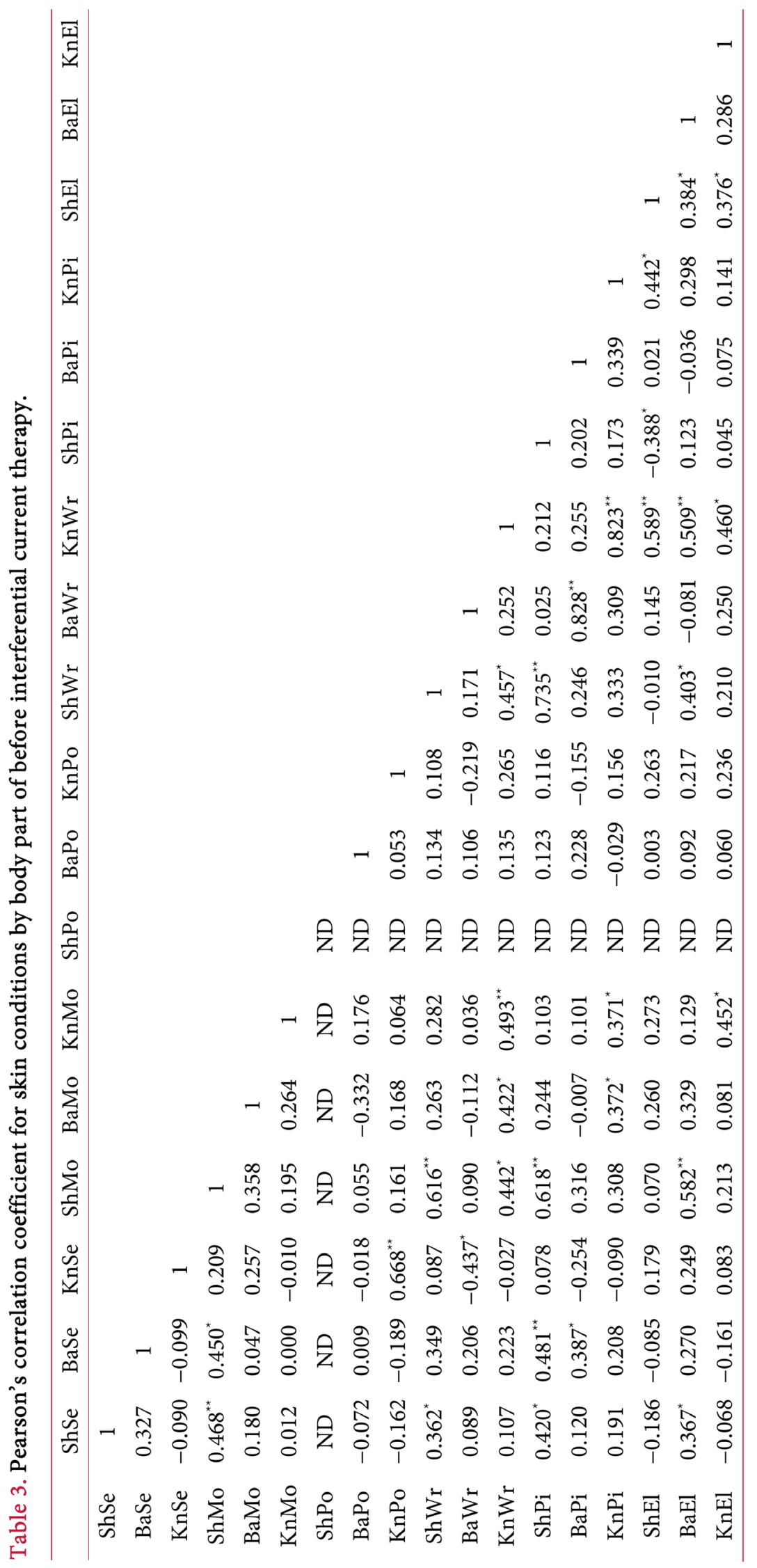




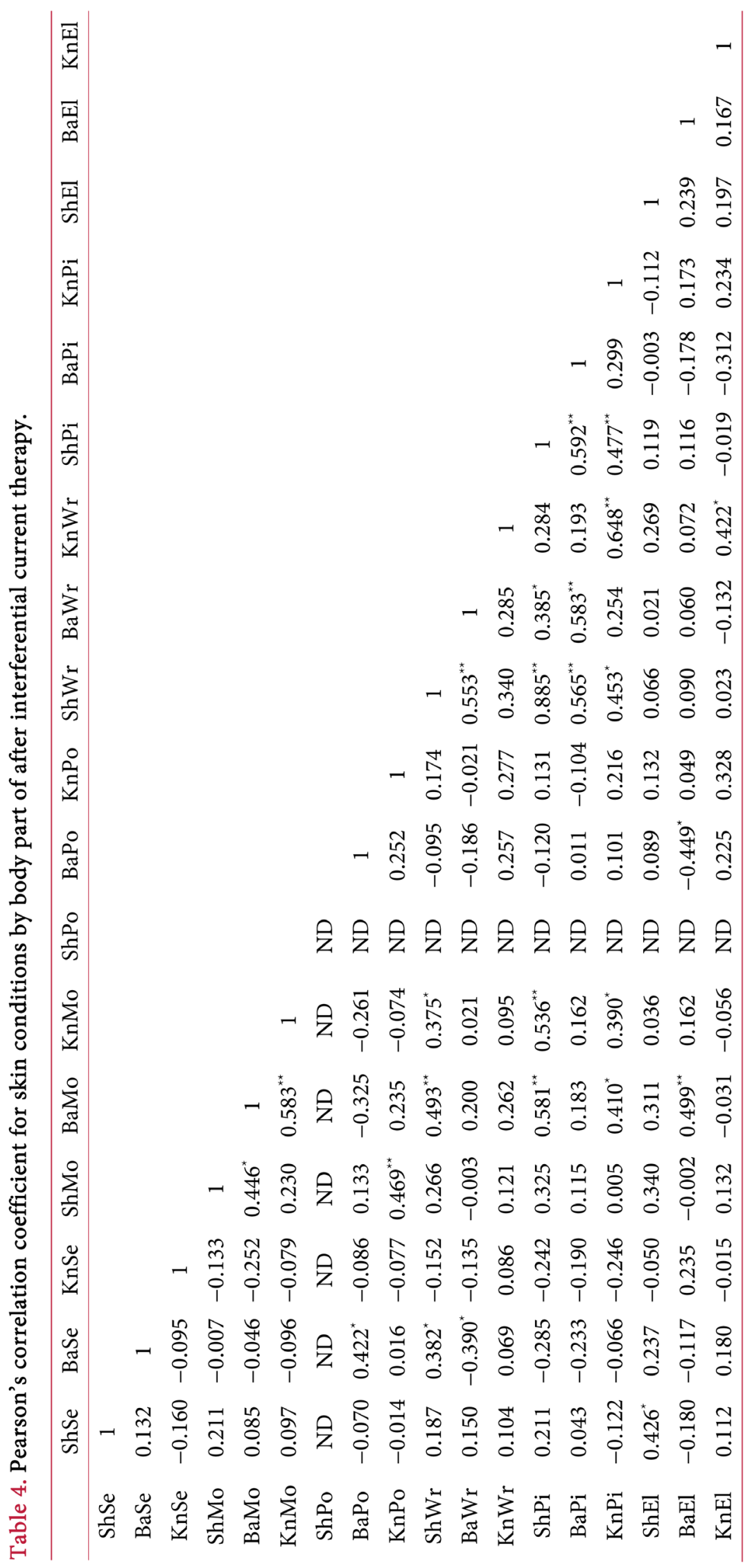




\section{DISCUSSION}

This study was a comparative analysis of skin condition differences induced by the application of ICT in healthy male volunteers. We compared the skin condition of Korean men in their 20s before and after the application of ICT. Measurements after the application of ICT showed significantly higher moisture levels as well as significantly higher wrinkle and pigmentation values. These results can be explained by the water retention that occurs within the tissue, which is essential to the maintenance its flexibility and to provide the necessary hydration for the enzymes involved in various aspects of stratum corneum maturation to function correctly [23]. There is evidence to indicate that ceramide 1 plays a pivotal role in barrier function [24]. The dry skin condition has been shown to be largely due to the inhibition of the corneodesmosomal degradative process, with the resultant retention of these binding complexes in the superficial layers of the stratum corneum $[15,23]$. The underlying cause appears to be a loss of water from the tissue owing to perturbations of one or both of the systems that are primarily responsible for maintaining stratum corneum water content; namely, the NMF and barrier lipid [15-19, 23, 24]. The cupping therapy is an ancient form of complementary, alternative medicine. One study reported that dry cupping therapy involves stimulation of the skin by suction. In this method, a partial vacuum is created by the production of heat within the cupping glass after it is applied to the skin. With dry or fire cupping, the cups are applied to intact skin [20,21]. By creating suction and negative pressure, cupping has been found to affect the body up to the depth of four inches into the tissues. Thus, it has been used to treat muscle pain and spasms, drain excess fluids and toxins, loosen adhesions, connective tissue and stubborn knots in soft tissue, stimulate blood circulation, and bring blood flow to nourish stagnant muscles and skin. In addition, it is said to enhance the flow of energy, stimulate the peripheral nervous system, activate the lymphatic system, clear colon blockages, help activate and clear the arteries, veins, and capillaries, and improve the health of varicose veins $[9,20,21,25]$. Furthermore, it can increase the levels of local blood and lymphatic circulation to relieve painful muscle tension [9]. Similarly, Noble et al. demonstrated the ability of ICT to improve blood flow in humans [26]. Such an increase in skin temperature has been previously suggested to be indicative of vasodilation that is due to decreased sympathetic nerve activity [25]. Ecchymosis and bleeding were the common immediate skin changes observed in cupping. These result from the breaking of the superficial blood vessels in the papillary dermis because of the negative pressure that creates the distinctive circular cutaneous lesions. The after-effects of cupping often include erythema, edema, and ecchymosis in a characteristic circular arrangement [22]. Most cupping therapies leave marks on the skin depending on the shape of the treatment tool. This is because the negative pressure leaves a mark on the skin and on the surrounding skin $[9,20,21,25]$. When we look at the differences in our study before and after ICT, it is helpful to know that it does change the skin condition based on measurements of healthy Korean men. Our correlation analysis showed that wrinkles and pigmentation were positively related. As the blood flow and blood vessel velocity changes, the skin is sucked in to the cups due to the negative pressure [21]. Our study is significant because it resulted in reference values and standardized measurements of the skin of various body parts; thus, these values provide knowledge about the skin condition and physiology of healthy Korean men that can be used for comparison in future studies. Further systematic and social scientific studies in the area of integumentary physiotherapy research and therapy are needed.

\section{CONCLUSION}

In the present study, our data showed that the changes in skin condition are associated with external stimulants. The effect of interferential current therapy on skin may differ depending on the part of the body, and some biophysical properties of skin vary depending on the location on the body.

\section{ACKNOWLEDGEMENTS}

We thank to the Yongin University students for supporting this work. There are actively supported by Dan-Ho academy. 


\section{CONFLICTS OF INTEREST}

The authors declare no conflicts of interest regarding the publication of this paper.

\section{REFERENCES}

1. Kim, J. and Kim, B (2010) Identification of Atrophy-Related Proteins Produced in Response to Cast Immobilization in Rat Gastrocnemius Muscle. Molecular \& Cellular Toxicology, 6, 361-371.

https://doi.org/10.1007/s13273-010-0048-8

2. Beatti, A., Rayner, A., Chipchase, L. and Souvlis, T. (2011) Penetration and Spread of Interferential Current in Cutaneous, Subcutaneous and Muscle Tissues. Physiotherapy, 97, 319-326.

https://doi.org/10.1016/j.physio.2011.01.008

3. Almeida, T.F., Roizenblatt, S., Benedito-Silva, A.A. and Tufik, S. (2003) The Effect of Combined Therapy (Ultrasound and Interferential Current) on Pain and Sleep in Fibromyalgia. Pain, 104, 665-672. https://doi.org/10.1016/S0304-3959(03)00139-8

4. Taylor, K., Newton, R.A., Personius, W.J. and Bush, F.M. (1987) Effects of Interferential Current Stimulation for Treatment of Subjects with Recurrent Jaw Pain. Physical Therapy, 67, 346-350. https://doi.org/10.1093/ptj/67.3.346

5. Lee, L.K., Jeon, H.J., Choi, Y.D., Kim, B. and Kim, J. (2013) Change in the Interferential Current Therapy-Induced Sensory Threshold on the Bodies of Elderly People. Toxicology and Environmental Health Sciences, 5, 41-47. https://doi.org/10.1007/s13530-013-0154-9

6. Goats, G.C. (1990) Interferential Current therapy. British Journal of Sports Medicine, 24, 87-92. https://doi.org/10.1136/bjsm.24.2.87

7. Fuentes, C.J., Armijo-Olivo, S., Magee, D.J. and Gross, D.P. (2011) A Preliminary Investigation into the Effects of Active Interferential Current Therapy and Placebo on Pressure Pain Sensitivity: A Random Crossover Placebo Controlled Study. Physiotherapy, 97, 291-301. https://doi.org/10.1016/j.physio.2011.01.001

8. Cheing, G.L., So, E.M. and Chao, C.Y. (2008) Effectiveness of Electroacupuncture and Interferential Eloctrotherapy in the Management of Frozen Shoulder. Journal of Rehabilitation Medicine, 40, 166-170. https://doi.org/10.2340/16501977-0142

9. Rahim, A.A.A. EI., Lkabalawy, M.A., Hassan, A.S.A.D. and Atta, H.K. (2017) Cupping Therapy versus Interferential Cupping Therapy on Mechanical Low Back Pain. International Journal of ChemTech Research, 10, 253-264.

10. Lambert. I., Tebbs, S.E., Hill, D., Moss, H.A., Davies, A.J. and Elliott, T.S. (2000) Interferential Therapy Machines as Possible Vehicles for Cross-Infection. Journal of Hospital Infection, 44, 59-64.

https://doi.org/10.1053/jhin.1999.0647

11. Jeon, H.J., Kim, J.H., Kim, B. and Kim, J. (2012) Analysis of High-Frequency Transcutaneous Electrical Nerve Stimulation-Induced Sensory Threshold from the Elderly People for Healthy Life. Toxicology and Environmental Health Sciences, 4, 167-172. https://doi.org/10.1007/s13530-012-0132-7

12. Mehta, V. (2015) The Effects of Interferential Stimulation on Pain and Motion after Shoulder Surgery: A Prospective Randomized Study. Surgical Science, 6, 464-469. https://doi.org/10.4236/ss.2015.610067

13. Treffene, R.J. (1983) Interferential Fields in a Fluid Medium. Australian Journal of Physiotherapy, 29, 209-216. https://doi.org/10.1016/S0004-9514(14)60672-3

14. Kim, S.J., Park, J.H. and Kim, J. (2017) Changes in Dermatological Characteristics of Skin Caused by Electroluminescent Infrared Heating Lamp in Healthy Korean Men. Toxicology and Environmental Health Sciences, 9, 141-151. https://doi.org/10.1007/s13530-017-0315-3 
15. Schario, M., Lünnemann, L., Stroux, A., Reisshauer, A., Zuberbier, T., Blume-Peytavi, U. and Garcia Bartels, N. (2014) Children with Dry Skin and Atopic Predisposition: Daily Use of Emollients in a Participant-Blinded, Randomized, Prospective Trial. Skin Pharmacology and Physiology, 27, 208-216. https://doi.org/10.1159/000360546

16. Kim, S.J., Yang, S.M., Kim, J.H., Lee, J.U., Kim, M.Y., Lee, L.K., Park, B.S., Lee, W.D., Noh, J.W., Shin, Y.S., Kim, D.H., Kim, I.H. and Kim, J. (2018) Characteristic Dermatologic Changes in the Condition of Skin after Ultrasonic Stimulation in Healthy Korean Men. Journal of Cosmetics, Dermatological Sciences and Applications, 8 (in Press).

17. Kim, S.J., Kim, J.H., Lee, J.U., Kim, M.Y., Lee, L.K., Park, B.S., Yang, S.M., Lee, W.D., Noh, J.W., Shin, Y.S., Kim, D.H., Kim, I.H. and Kim, J. (2018) Analysis of Skin Parameters of Korean Men According to the Parts of the Body for Integumentary Physiotherapy Research. Health, 10, 467-486.

https://doi.org/10.4236/health.2018.104038

18. Man, M.Q.M., Feingold, K.R., Thornfeldt, C.R. and Elias, P.M. (1996) Optimization of Physiological Lipid Mixtures for Barrier Repair. Journal of Investigative Dermatology, 106, 1096-1101. https://doi.org/10.1111/1523-1747.ep12340135

19. Imokawa, G., Abe, A., Jin, K., Higaki, Y., Kawashima, M. and Hidano, A. (1991) Decreased Level of Ceramides in Stratum Corneum of Atopic Dermatitis: An Etiologic Factor in Atopic Dry Skin? Journal of Investigative Dermatology, 96, 523-526. https://doi.org/10.1111/1523-1747.ep12470233

20. Cao, H., Han, M., Li, X., Dong, S., Shang, Y., Wang, Q., Xu, S. and Liu, J. (2010) Clinical Research Evidence of Cupping Therapy in China: A Systematic Literature Review. BMC Complementary and Alternative Medicine, 10, 70. https://doi.org/10.1186/1472-6882-10-70

21. Yoo, S.S. and Tausk, F. (2004) Cupping: East Meets West. International Journal of Dermatology, 43, 664-665. https://doi.org/10.1111/j.1365-4632.2004.02224.x

22. Rubaye, K.Q.A.A. (2012) The Clinical and Histological Skin Changes after the Cupping Therapy (AI-Hijamah). Journal of the Turkish Academy of Dermatology, 6, 1-7.

23. Harding, C.R., Watkinson, A., Rawlings, A.V. and Scott, I.R. (2000) Dry Skin, Moisturization and Corneodesmolysis. International Journal of Cosmetic Science, 22, 21-52. https://doi.org/10.1046/j.1467-2494.2000.00001.x

24. Holleran, W.M., Takagi, Y. and Uchida, Y. (2006) Epidermal Sphingolipids: Metabolism, Function, and Roles in Skin Disorders. FEBS Letters, 580, 5456-5466. https://doi.org/10.1016/j.febslet.2006.08.039

25. Wong, R.A. and Jette, D.U. (1984) Changes in Sympathetic Tone Associated with Different Forms of Transcutaneous Electrical Nerve Stimulation in Healthy Subjects. Physical Therapy, 64, 478-482. https://doi.org/10.1093/ptj/64.4.478

26. Noble, J.G., Henderson, G., Cramp, A.F., Walsh, D.M. and Lowe, A.S. (2000) The Effect of Interferential Therapy upon Cutaneous Blood Flow in Humans. Clinical Physiology, 20, 2-7. https://doi.org/10.1046/j.1365-2281.2000.00207.x 